\title{
Weather-Index Drought Insurance in Burkina-Faso: Assessment of Its Potential Interest to Farmers
}

\author{
AleXIS BERG \\ Laboratoire d'Océanographie et du Climat: Expérimentations et Approches Numériques, \\ Institut Pierre-Simon Laplace, Paris, France \\ PHILIPPE QUIRION \\ Centre International de Recherche sur l'Environnement et le Développement, Nogent-sur-Marne, and \\ Laboratoire de Météorologie Dynamique, Institut Pierre-Simon Laplace, Paris, France \\ BENJAMIN SULTAN \\ Laboratoire d'Océanographie et du Climat: Expérimentations et Approches Numériques, \\ Institut Pierre-Simon Laplace, Paris, France
}

(Manuscript received 22 January 2009, in final form 13 May 2009)

\begin{abstract}
By using a detailed agricultural and climate dataset over Burkina-Faso and simple assumptions regarding the form of an insurance contract, the authors investigate the potential economic efficiency for farmers of a weather-index insurance system in this country. To do so, the results of more than 3000 simulated contracts applied to 30 districts, 21 yr (1984-2004), and five crops (cotton, millet, sorghum, maize, and groundnut) are explored. It is found that such an insurance system, even based on a simple weather index like cumulative rainfall during the rainy season, can present a significant economic efficiency for some crops and districts. The determinants of the efficiency of such contracts are analyzed in terms of yield/index correlations and yield variability. As a consequence of these two main determinants, the farmer's gain from an insurance contract is higher in the driest part of the country. In the same way, maize and groundnuts are the most suitable to implement an insurance system since their respective yields show a large variance and a generally high correlation with the weather index. However, the implementation of a real weather-index insurance system in West Africa raises a number of key practical issues related to cultural, economic, and institutional aspects.
\end{abstract}

\section{Introduction}

In the Sudano-Sahelian part of Western Africa, rain-fed crop production remains the principal source of households' food and income: $70 \%$ of the income according to Abdulai and CroleRees (2001) in southern Mali, 67\% according to Wouterse and Taylor (2007) in central Burkina Faso. This production is highly dependent on climate, as means to control the crop environment are largely unavailable to farmers. Irrigation is rarely an option $[4 \%$ of cultivated land in sub-Saharan Africa according to the World Bank (2007)] and the use of mechanization, fertilizers, and other off-farm inputs is

Corresponding author address: Alexis Berg, LOCEAN, Boîte 100 - 4, place Jussieu, 75005 Paris, France.

E-mail: alexis.berg@locean-ipsl.upmc.fr low (Ingram et al. 2002). Hence, West African farmers are vulnerable to climate variability: large variability in monsoon rains often results in large variability in crop yields. This vulnerability is aggravated by a food deficit crisis resulting from a rapidly growing population combined with an insufficient increase in yields of millet and sorghum, the main source of food and income of the Sahelian people, over the last few decades (De Rouw 2004), leading to a decrease of food production per capita (World Bank 2007). Hence, the long-term and large-scale drought of the 1970s and 1980s (e.g., Dai et al. 2004), which stands as the greatest regional climatic signal over the second half of the last century in terms of precipitation (Trenberth et al. 2007), had dire consequences for local populations. Although rainfall has somewhat recovered since the late 1990s, drought conditions still have not ended in the region, and rainfall variability has 
increased during the last decades (Dai et al. 2004). In addition, although substantial uncertainties remain in the projected evolution of rainfall over West Africa (Cook and Vizy 2006), it is anticipated that future global climate change will negatively affect the region's agriculture and development (e.g., Adger et al. 2007).

To protect themselves against adverse effects of climate variability, West African farmers engage in a variety of risk management and coping strategies, for example, through income diversification, crop diversification, livestock holdings, crop storage, and informal credits (cf. Sakurai and Reardon 1997, and references therein). However, as shown by Sakurai and Reardon (1997), these strategies are not always sufficient. Drought insurance might be a way to mitigate these adverse events, by providing an indemnity to farmers in dry years. Moreover, farmers tend to adopt farming practices that minimize the risk of crop failure rather than improve the average yield (De Rouw 2004). By covering the risk of climatically induced crop failure, agricultural insurance could encourage farmers to adopt riskier but more productive strategies.

Traditional agricultural insurance, based on damage assessment, suffers from an information asymmetry between the farmer and the insurer, especially moral hazard, and from the cost of damage assessment. As a consequence, such insurance schemes are limited to very specific risks (e.g., frost or hail) or rely on massive subsidies by public authorities, as in the United States or Canada (Hartell et al. 2006). Naturally, low-income countries' governments do not have the financial resources to distribute such subsidies. Moreover, these subsidies create an economic distortion and may push farmers to take excessive risks (McLeman and Smit 2006).

An emerging alternative is insurance based on a weather index (e.g., Skees et al. 1999), which is used as a proxy for crop yield. In such a scheme, the farmer, in a given geographic area, pays an insurance premium every year, and receives an indemnity if the weather index of this area falls below a determined level (the strike). ${ }^{1}$ It does not suffer from the two shortcomings mentioned above: the weather index provides an independent, objective, and relatively inexpensive assessment of crop damages. However, its weakness is the basis risk (i.e., the imperfect correlation between the weather index and the yields of farmers contracting the insurance). The basis risk can be considered the sum of two risks: first, the risk resulting from the index not being a perfect

\footnotetext{
${ }^{1}$ It should be noted, however, that weather-index insurance contracts can also be constructed, similarly, against excessive high levels of an index.
}

predictor of yield in general (the model basis risk); and second, the spatial basis risk - the index may not capture the weather effectively experienced by the farmer, all the more so if the farmer is far from the weather station(s) measuring the index.

Such weather-index insurances and weather derivatives (similar to risk-transfer mechanisms on the financial markets) have been used by energy suppliers in North America since the late 1990s, to hedge against a loss in profitability induced by abnormal weather (Hartell et al. 2006). Today, an increasing number of such index-based risk-transfer products are being provided for developing countries' farmers. Barnett et al. (2008) list 21 index insurance projects that have been planned, or implemented in pilot stages, in low- or middle-income countries, that are hedging against different risk events, with different index measures and target users. In terms of rainfallbased drought insurance for smallholder farmers, the only operational example so far has been in India since 2003, where it has encountered a growing success: 250000 policies were sold in India in 2005-06, with a premium volume of $\$ 17$ million (U.S. dollars), according to Barnett and Mahul (2007).

In parallel to this development, increasing attention has been given to the subject in the literature. Mahul (2001), in a theoretical framework, derives an optimal insurance contract against a climatic risk in the presence of an uninsurable and dependent aggregate production risk. Barnett et al. (2008) analyze the opportunities presented by index-based risk-transfer products to limit poverty traps. Most other papers have a more specific geographical focus. Turvey (2001) studies weather derivatives to hedge rain- and heat-based weather risk for agriculture in Ontario, Canada. Vedenov and Barnett (2004) analyze the efficiency of weather derivatives as insurance instruments for corn, cotton, and soybeans in six districts located in the United States. Giné et al. (2007) analyze the statistical distribution of indemnities in the case of the weather-index insurance system implemented in India in 2003. They suggest that this contract acts like disaster insurance, providing rare but very high payouts during the most extreme rainfall events. Skees et al. (2007) consider how the use of index-based risk-transfer products could improve microlending in Peru and Vietnam. Chantarat et al. (2007) suggest using weather-index insurance to improve drought response for famine prevention in Kenya. Finally, Deng et al. (2007) analyze a weather-based index insurance to protect against dairy production losses caused by heat stress. In addition to these papers in refereed journals, a number of reports and feasibility studies are available (e.g., Skees et al. 2001; Hartell et al. 2006; Hess et al. 2005; Osgood et al. 2007; and Barrett et al. 2007) that also provide useful 
information, albeit with a sometimes more practicaloriented frame of mind. For instance, Osgood et al. (2007) seek to design index-based insurance contracts for the pilot project in Malawi, by minimizing farmers' income variance given an insurance price constraint.

In the present study, we adopt a more theoretical and general approach, and try to evaluate the potential of weather-index insurance in West Africa for several crops over a whole country. To do so, we use historical climate and crop data to try and design, ex post, insurance contracts that are optimal from the farmer's point of view, under some simple and common assumptions regarding the form of the insurance contract, a participation constraint by the insurer, and the utility function of a representative farmer. We chose Burkina Faso as a case study because of the availability of an extended crop and weather dataset over this country, covering the recent decades (1984-2004) with a high spatial resolution (45 districts). We identify optimal insurance contracts, designed at the district scale, for five crops: cotton, millet, sorghum, maize, and groundnut.

We stress that this analysis should not be seen as a project study: our intention is not to deliver an operational insurance product, but to use a simple modeling framework to explore the potential of index insurance in Burkina-Faso. The questions we address are the following: Is it possible, a posteriori, to design realistic insurance contracts that would benefit the farmers? Where, and for what crops, can we define contracts that are of most benefit to the farmers? What determines this potential economic gain? The practical issues associated with the implementation of drought insurance in Sahelian agriculture, in particular the constraints that arise from cultural, economic, and institutional aspects, are beyond the scope of such an analysis. We will discuss them in the concluding section.

\section{Material and methods}

\section{a. Agricultural and weather data}

The agricultural database from the General Department of Agricultural Forecasts and Statistics of BurkinaFaso (AGRISTAT) provides us with annual production, area under cultivation, and yield for several crops in Burkina-Faso: millet, sorghum, cotton, groundnuts, maize, etc. from 1984 to 2004 (available online at http://agristat.bf. tripod.com/). Data are given at the district level, of which there are 45 (see map on Fig. 2). However, the database suffers from some missing values, with different numbers of missing values for different crops.

In the frame of the African Monsoon Multidisciplinary analysis (AMMA; http://amma-international.org/) project, the AGRHYMET Centre (http://www.agrhymet.ne/) pro- vides us with 1971-2006 rainfall data at a 10-day resolution from its network of rain gauges over the Sahel. From the map on Fig. 1, one can see that Burkina-Faso is densely sampled, with nearly 150 weather stations over the country. We associate rainfall stations in Burkina-Faso with the corresponding districts according to their spatial coordinates. Mean annual rainfall across the country ranges from roughly $400 \mathrm{~mm}$ in the north to $1100 \mathrm{~mm}$ in the south.

As a result, there are for each crop between 23 (cotton) and 30 (millet) districts where crop data and rainfall time series are available over 1984-2004, with 1.2 missing years on average, and a maximum of 4 missing years. There are between one and eight rainfall stations per district. When several stations are available, we simply take the average value, since we do not have any information on the spatial distribution of cultivated areas within districts.

Prices for the different crops are taken from the Réseau des Systèmes d'Information des Marchés en Afrique de l'Ouest (RESIMAO; the official West African Market Price Agencies online; http://www.resimao.org). Note that since we are only interested in risks related to weather, we assume constant prices throughout the period. This simplification means that farmers' income is proportional to yields.

\section{b. Methods and assumptions}

As in India, we consider that the insured party is an individual farmer. We assume a representative farmer with a Constant Relative Risk Aversion (CRRA) utility function as the objective criterion, which appears appropriate to describe the farmer's behavior, as shown by the statistical tests performed by Chavas and Holt (1996) and Pope and Just (1991). Under this assumption, the farmer maximizes the expected utility:

$$
\operatorname{EU}\left(\left\{x_{i}\right\}\right)=\operatorname{Mean}\left[\frac{\left\{x_{i}\right\}^{1-r}}{1-r}\right],
$$

where $\left\{x_{i}\right\}$ is the ensemble of possible farmer incomes, assumed to have the same probability of occurrence, $i$ indicates a particular realization (a year), and $r$ is the coefficient of relative risk aversion. ${ }^{2}$

In year $i$, the farmer's income without insurance $x_{i}$ is

$$
x_{i}=a\left(\mathrm{cp} y_{i}-c\right),
$$

where $a$ is the area cultivated, cp is the crop price, $c$ is the production cost, and $y_{i}$ is the yield in year $i$. For $\left\{y_{i}\right\}$ we

\footnotetext{
${ }^{2}$ The relative risk aversion coefficient of a utility function $u(x)$ is defined as $-x\left(\partial^{2} u / \partial^{2} x\right) /(\partial u / \partial x)$ (Chavas and Holt 1996, p. 333). Note that $\operatorname{EU}\left(\left\{x_{i}\right\}\right)$ tends to Mean $\left[\log \left(\left\{x_{i}\right\}\right)\right]$ when $r$ tends to 1 .
} 


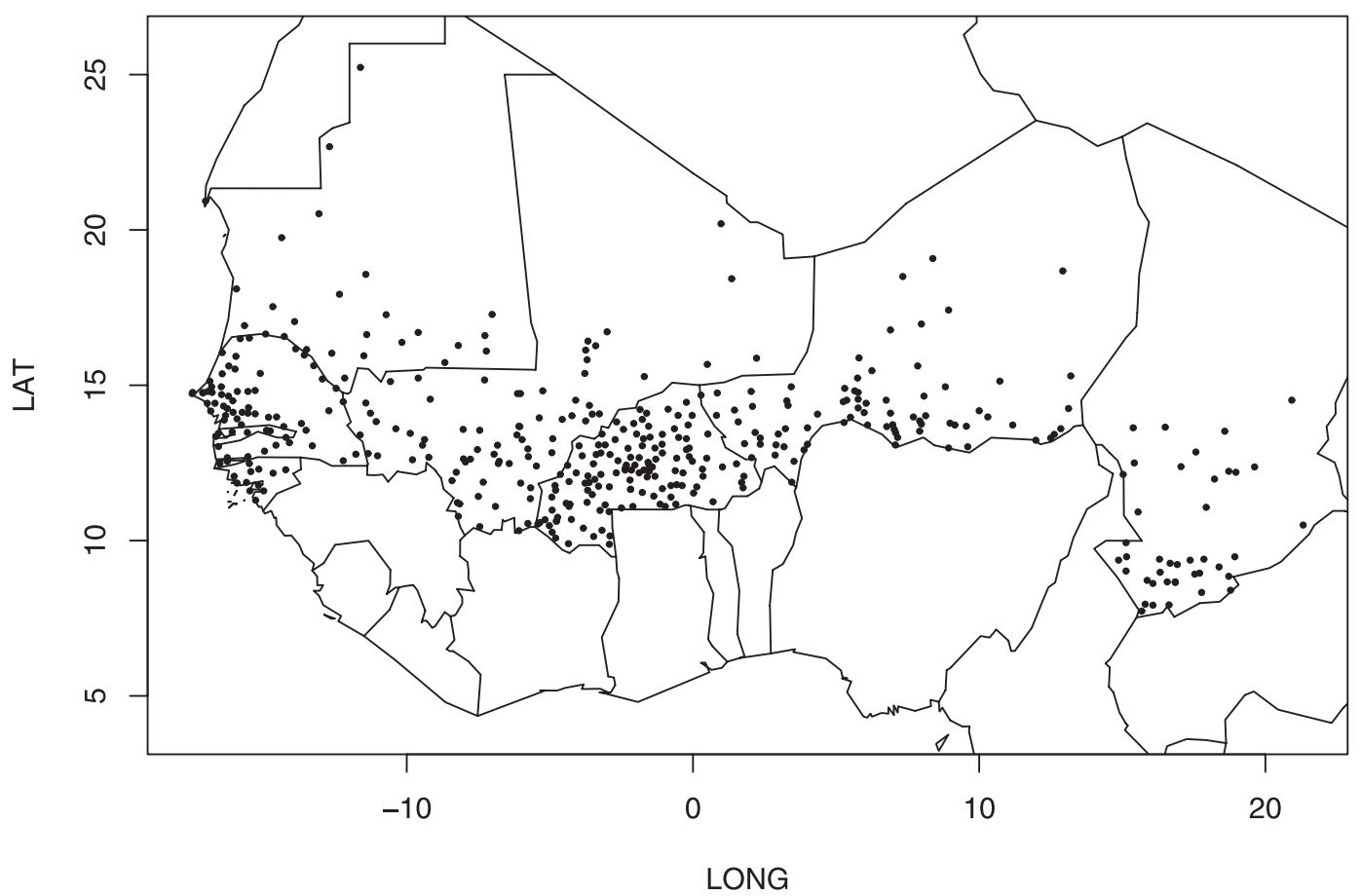

FIG. 1. Localization of the rainfall stations of the AGRHYMET network over the Sahel.

take the historical series of yield available (at most 1984-2004) for each crop and district.

The higher the $r$, the more risk averse the farmer is. Since risk aversion can be defined as one's preference for a bargain with a certain payoff over another bargain with an uncertain but possibly higher payoff, the farmer's benefit from a given insurance contract will, all other things being equal, increase with increasing risk aversion. The risk aversion may differ across populations, but we did not find any empirical study on West African farmers. According to Gollier (2003), estimates of $r$ typically range from 2 to 4 . We take the conservative value of $r=2$, so that the benefits from the insurance we compute can be seen as lower bounds. To test the sensitivity of our results to $r$, we also perform the computations with $r=1$ and $r=3$.

From (2), one can compute the certainty-equivalent income (CEI; i.e., the certain income that provides the same utility as a given probability distribution of uncertain incomes):

$$
V(\mathrm{EU})=(1-r) \mathrm{EU}^{1 / 1-r} .
$$

In year $i$, the farmer's income with insurance $x a_{i}$ is

$$
x a_{i}=a\left(\operatorname{cp} y_{i}-c-p+\text { Indemnity }_{i}\right)
$$

where $p$ is the insurance premium, assumed equal to

$$
p=1.3 \text { Mean }\left[\text { Indemnity }_{i}\right]
$$

Equation (5) means that we compute the contract under the constraint that the insurer's margin is $30 \%$ of the average indemnity. Thus, over the years the sum of annual premiums paid by the farmer is $30 \%$ higher than the sum of the indemnities he receives: this is the price of the risk transfer. This is the current practice in insurance according to Gollier (2003). Although available documents for actual weather-index insurance contracts generally do not provide an accurate description of how insurers shape the contracts and build their margins, ${ }^{3}$ this $30 \%$ margin hypothesis does not seem unrealistic, and has the merit of simplicity.

We then use a typical contract shape, similar to those used in the insurance projects in Malawi and in Ethiopia, ${ }^{4}$ with two thresholds [Eq. (6) and Fig. 3]. A contract is

\footnotetext{
${ }^{3}$ The insurance margin used in existing weather-index insurance schemes is generally not disclosed. Osgood et al. (2007, p. 34) provide a formula used in Malawi to compute a "pseudo-price" representing the cost of the risk for the insurer. The application of this formula in our context, as well as in Malawi, leads to a margin of around $10 \%$. However, this is not meant to be the definitive price, "e.g., because of taxes and fees." Our higher margin of $30 \%$ should be seen as a more "complete" price, including the administration cost of the scheme.

${ }^{4}$ The contracts used in India are a bit more complicated, with a third threshold (Giné et al. 2007).
} 
described by three parameters, $S, X$, and $P$ : when the weather-index $I_{i}$ falls below the first threshold (the strike $S$ ), the farmer receives an indemnity, equal to the difference between the index and the strike multiplied by a tick, $P$. However, the indemnity cannot be greater than a maximum value $M=(S-X) P$, where $X$ is a saturation threshold, under which indemnities do not increase any more. This is meant to account for the saturation of damages when the index is too low (typically, total loss of crop production). Hence we have

$$
\text { Indemnity }_{i}=\operatorname{Min}\left[\operatorname{Max}\left(0, S-I_{i}\right) P, M\right] .
$$

For every crop and district, we compute the gains in CEI for a range of parameters $S, X$, and $P$. The optimal contract corresponds to the set of parameters that maximize the expected utility [Eq. (1)] and satisfy Eqs. (4), (5), and (6). If no set of parameters can be found that increases the farmer's utility, the solution of the optimization is "no insurance" and the gain of CEI is nil.

The weather index we consider is the cumulative seasonal (April-October) rainfall over the district. This is quite a simple index; however, using more complex indices, such as results from a water budget model (Ward et al. 2008) or a crop model, would have required more detailed meteorological data, which were not available or easily computable, such as potential evapotranspiration. Similarly, it could have seemed more relevant to compute a cumulative rainfall index only over critical parts of the crop cycle. However, this would require a precise knowledge of the timing of these cycles, and thus require fine agricultural data such as sowing dates, which we did not have over this period. In addition, correlations between district yields and monthly rainfall totals were not stronger, whatever the month, than correlations with the seasonal index. Finally, since this simple index is not adjusted to fit one particular crop production time series, it allows us to consider several different crops with the same index. Here, it appeared that cumulative rainfall is not a good weather index for cotton: correlations between cotton yields and annual rainfall remain low for all districts in Burkina-Faso, and so are the performances of simulated insurance contracts. This is consistent with previous studies on the main climatic drivers of cotton production (Blanc et al. 2008; Sultan et al. 2009), which found that cumulative rainfall is poorly correlated to cotton yields. Hence, in the rest of the paper, we only focus on the other four crops.

However, because the mathematical optimization can lead to unrealistic solutions with frequent large payoffs and very high premiums, we found it necessary to add two broad constraints to the optimization to retain realistic solutions. First, a liquidity constraint: the annual pre- mium cannot exceed $20 \%$ of the farmer's mean income (without insurance). The farmer might not be able, or willing, to allocate too much of his income to an insurance policy, even if the resulting indemnities are accordingly important. The other constraint is that the number of years with payouts must not exceed half of the total time series. Indeed, the purpose of the insurance contract is precisely to compensate for the few worst years only. Moreover, the transaction costs for the insurer, which are not accounted for in our computation, increase with the frequency of payouts. We assess the importance of these constraints for the results by repeating the optimization with lower values $(10 \%$ for the liquidity constraint and a maximum average payout frequency of $25 \%$ ).

We then consider that a gain of CEI of a few percent (typically more than $2 \%$ ) corresponds to a viable contract for the insured party. Because our approach only yields an in-sample optimized value of the farmer's CEI increase, it would be necessary to perform an out-of-sample evaluation of these optimized contracts. However, the agronomic data necessary for such an analysis were not available to us. The $21 \mathrm{yr}$ of crop data available for Burkina-Faso are too short to be separated into two independent datasets. Therefore, to get a hint of the extent to which in-sample overfitting affects our results, we repeat the optimization, with the same assumptions but with a leave-one-out procedure: that is, for each 21-yr district/crop series, the optimization is repeated over the 21 possible 20-yr series (each year is alternately withdrawn from the original series). The 21 resulting contracts are respectively applied to the $21 \mathrm{yr}$ excluded from the corresponding optimizations (these years then remain "unseen" during the optimizations). The final result is a combination of $21 \mathrm{yr}$ with indemnities and premiums that can be compared to the original optimized contract. Overfitting would result in leave-one-out contracts being largely different from the initial ones. Given the timeconsuming nature of such a procedure, however, we only conduct this analysis on a subset of the data, that is, for each crop the four districts where the optimized contracts perform best with the best index/yield correlations.

\section{Results}

\section{a. Gains of CEI from the insurance}

Figure 2 shows the gains of CEI on the district scale for the different crops. It appears that the economic interest of the insurance contracts varies a lot across crops and districts. For all crops, most of the viable contracts are in the northern districts of Burkina-Faso. The highest gains of CEI are obtained for maize and groundnuts, the maximum being groundnuts in the province of Sissili (103.4\%). Figure 3 shows an example 


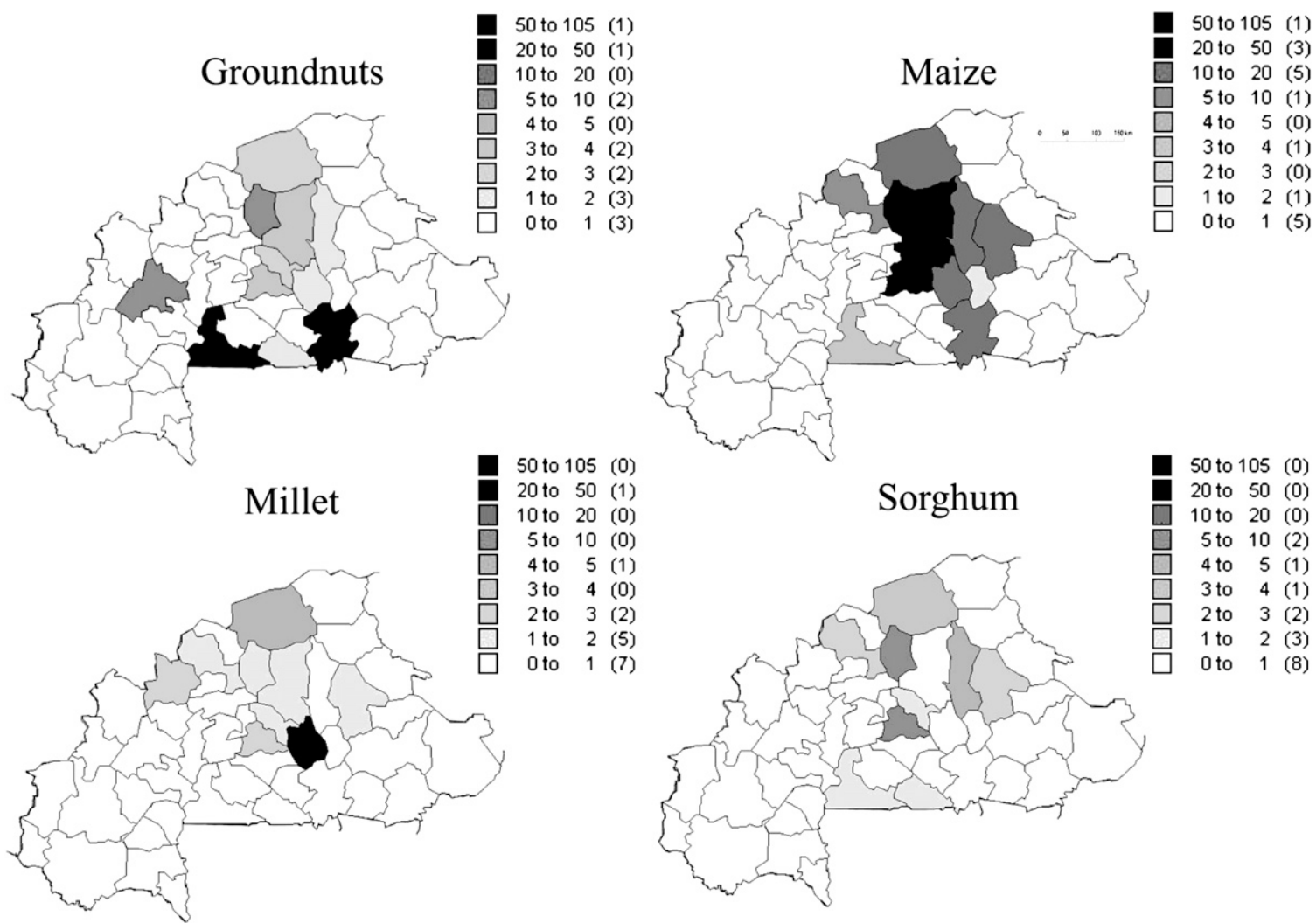

FIG. 2. Gains of CEI over 1984-2004 (\%) for different crops on the district scale. Figures in brackets are the counts in each interval. The gray shades are the same on the four maps. Districts in white correspond to missing data (mainly yields), i.e., 15 districts out of 45.

of a successful contract, for sorghum, on the Bam district. Years with crop failures are correctly compensated (Fig. 3, bottom left). The increase of CEI is $5.18 \%$, for an annual premium of 10513 Franc de la Communauté Financière Africaine (FCFA). ${ }^{5}$ Table 1 shows the mean gain of CEI over Burkina-Faso for each crop. Over all districts and crops, the average gain of CEI from insurance is more than $5 \%$. On average, maize and groundnuts show higher gains than millet and sorghum (Table 1).

However, these average figures hide large distributions. Out of a total of 112, only 34 contracts show a gain in CEI of more than 2\% (Fig. 2). Among these, 14 are contracts for maize. For certain districts, with the index we define and under our assumptions, no insurance contract is possible (the gain of CEI is then zero).

Table 2 shows that, on average, the gain in CEI is reduced when applying a leave-one-out procedure. This is, to a certain extent, expected, as less information (20 out of $21 \mathrm{yr}$ ) is used as input in a cross-validated analysis. Although the decrease is here probably larger than this simple effect, meaning that the 21-yr optimized contracts

\footnotetext{
${ }^{5} \$ 1$ is currently around 500 FCFA.
}

are to a certain extent overfitted on the historical data, the gains of CEI remain positive and of the same order of magnitude-with the notable exception of groundnuts. For groundnuts, the gain of CEI disappears (and even turns to a loss): this means that the results over 1984-2004 are largely dependent on this very time period and series. This does not seem to be the case for the other crops.

For illustration, Fig. 4 shows the income series with and without insurance on the Bam district for sorghum (similar to Fig. 3), from the optimized contract (top panel) and from the leave-one-out contract (bottom panel). One can see that in this case the timing and amplitude of indemnities remain similar. Note that in the leave-one-out contract the premium value changes from year to year, since it each time results from a different 20 -yr contract. This supplementary degree of freedom in the optimization even allows the final gain of CEI to be greater $(6.7 \%$ instead of $5.18 \%$ ), but this is only the case in this particular example.

Hence, we feel confident that overfitting of the optimization on the available yield and rainfall data does not significantly bias our results. Should the rainfall distribution remain stationary beyond the optimization period used here (1984-2004), this means that the actual gains in 
Sorghum, district of BAM
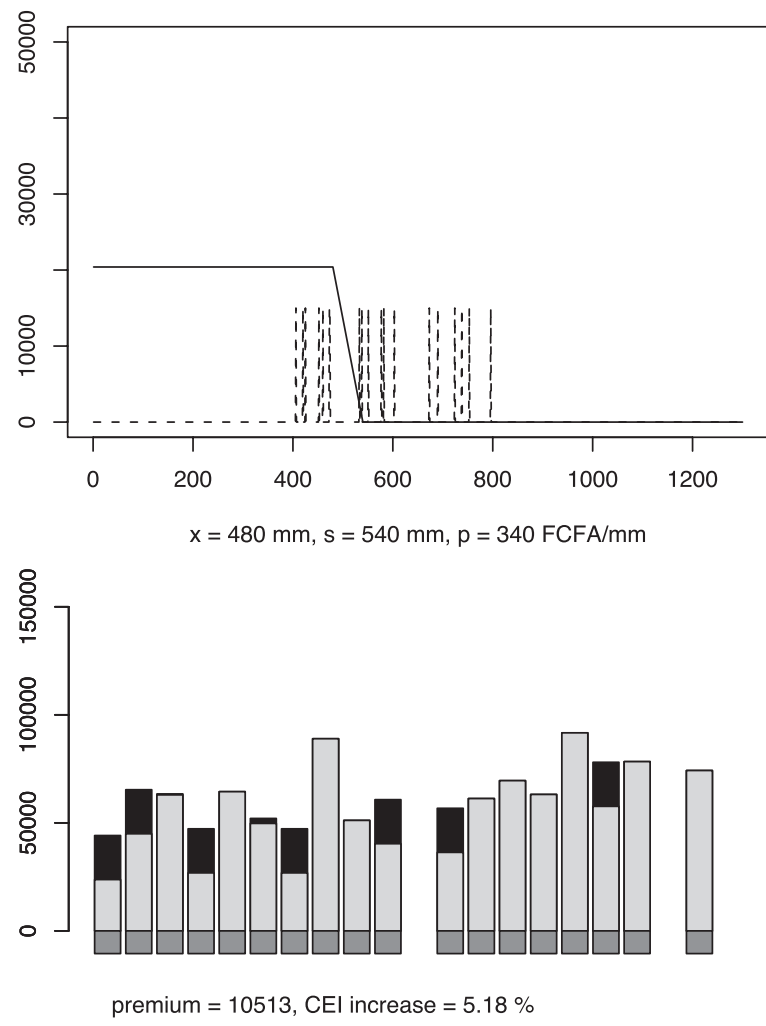
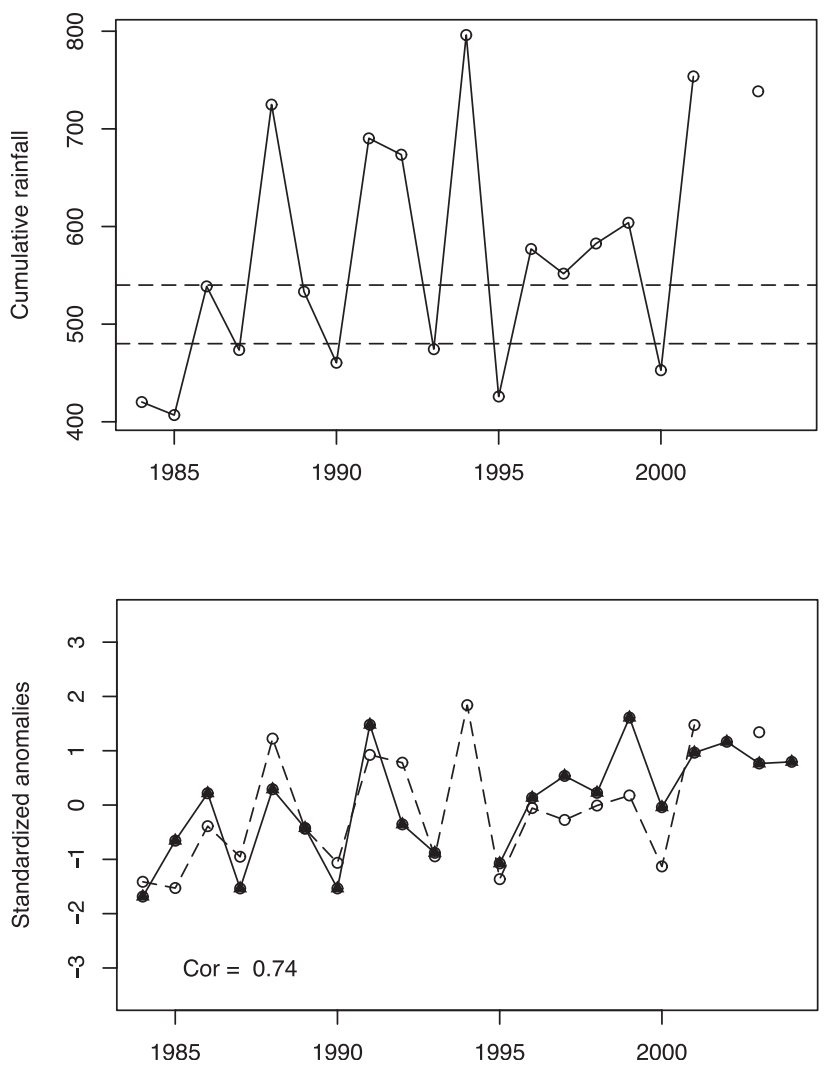

FIG. 3. Contract for sorghum, district of Bam, over 1984-2004. (top left) Dashed lines are the distribution of annual rainfall amounts, full line shows the shape of the insurance contract (indemnity, in FCFA, as a function of cumulative rainfall, in mm); (top right) full line is annual rainfall $(\mathrm{mm})$, the dotted lines show the $x$ and $s$ parameters of the contract; (bottom left) light gray bars represent income without insurance, black bars are indemnities, and dark gray bars show the annual premium (in FCFA); and (bottom right) yields (full line) and rainfall index (dashed line), expressed in standardized anomalies $\{[X-\operatorname{mean}(X)] / \operatorname{std}(X)\}$.

CEI after 2004 would not significantly differ from those presented here. On the contrary, if rainfall does not remain stationary in the future, the contracts will have to be redesigned. However, the problem of weather insurance actualization over time, particularly in the context of climate change, is beyond the scope of this study.

\section{b. Sensitivity to optimization parameters}

As mentioned in section 2, we performed the optimization with different values of $r$. Table 3 shows that the sensitivity of gains in CEI to $r$ is large: gains nearly triple when changing $r$ from 2 to 3 , and are dramatically reduced when $r=1$. The decrease mostly affects contracts with high gains of CEI: for example, the increase in CEI over the Bam district for maize falls from $82 \%$ to $11.5 \%$ when $r$ decreases from 2 to 1 . Practically, this means that farmlevel investigations are needed to more precisely estimate the risk aversion of African farmers and assess their gain of CEI from drought insurance. However, these changes in mean gain simply result from the results being simultaneously shifted downward (or upward). The differences between crops remain similar, and the relationships analyzed in the section $3 \mathrm{c}$ still hold true, as $r$ changes.

Table 4 similarly presents the sensitivity of simulated gains of CEI to the constraints on maximum payout frequency and premium amount specified in the model. Results are overall not very sensitive to these assumptions: they only act on a limited number of optimized contracts. The most important constraint seems to be the one on maximum payoff frequency, as gains of CEI slightly decrease when this constraint is tightened from $50 \%$ to $25 \%$. Similar to the sensitivity to $r$, contracts generating a high CEI increase are mostly affected. This suggests that, in a number of cases, the optimum indemnity frequency for the farmer is higher than $25 \%$. However, the administrative costs for the insurer increase with payout frequency, and insurers would probably be reluctant to implement contracts that generate 
TABLE 1. Mean gain of CEI over all districts (\%) for each crop.

\begin{tabular}{lcccc}
\hline \hline & Millet & Sorghum & Maize & Groundnuts \\
\hline $\begin{array}{l}\text { Mean countrywide } \\
\text { gain in CEI (\%), } \\
\text { district-based contracts }\end{array}$ & 2.04 & 1.27 & 11.4 & 6.94 \\
\hline
\end{tabular}

payouts more than $25 \%$ of the time (Osgood et al. 2007). On the other hand, the contracts must meet the expectations of farmers: in particular, strings of years without indemnities would progressively dissuade farmers from paying premiums every year. In theory there is, for a given insurance price, a balance between low and frequent payouts and higher and less frequent payouts. Therefore, ranges for payout frequency, as well as for price constraint, should be determined through interviews with financial stakeholders and farmers (Osgood et al. 2007).

\section{c. Determinants of CEI increase}

In an index-based insurance scheme, the weather index is supposed to act as a surrogate for crop yields. This means that the efficiency of the insurance contract first depends, a priori, on the strength of the correlation between the index and the yield. Figure 5a shows that, as expected, the gain in certainty-equivalent income is overall an increasing function of the correlation between index and yield. However, good correlations do not necessarily imply viable contracts: some contracts with high correlations do not provide any substantial increase in CEI. For example, the Gourma district, for millet, has a correlation of 0.76 but a CEI increase of only $0.1 \%$. Conversely, a contract can provide a significant increase in CEI despite a low correlation: for example, the Oubritenga district for maize shows a correlation of 0.35 , but a gain of $48.6 \%$. Indeed, what matters more than the accurate correlation between index and yield, is the fact that for low-yield years the index defines an important indemnity. The correlation for high-yield years does not really matter as long as the index is above the strike. Conversely, a high correlation does not imply a great increase in CEI if crop failures are negligible. Hence, it appears that the relationship between insurance efficiency and index/yield correlation is not straightforward.

The gain in CEI also tends to increase with an increasing coefficient of variation $(\mathrm{CV}$; ratio of standard deviation to mean) of farmers' income (Fig. 5b). Note that since we assume a constant price for crops, income $\mathrm{CV}$ is equivalent to yield $\mathrm{CV}$. Because income variability can be considered a measure of risk for the farmers, an insurance system is all the more effective when the crop yields are more variable. This relationship seems
TABLE 2. For each crop, average gain of CEI (\%) for the four districts where contracts perform best, (left columns) when optimized over 1984-2004, and (right columns) following a leave-oneout procedure over the same period.

\begin{tabular}{llllllll}
\hline \hline \multicolumn{2}{c}{ Millet } & \multicolumn{2}{c}{ Sorghum } & \multicolumn{2}{c}{ Maize } & \multicolumn{2}{c}{ Groundnut } \\
\hline 2.41 & 1.43 & 3.06 & 2.32 & 28.8 & 21.2 & 7.01 & -2.8 \\
\hline
\end{tabular}

here even clearer than the relation between gain of CEI and index/yield correlation. Comparison between Tables 1 and 5 shows that on average, crops with larger $\mathrm{CV}$ show higher gains of CEI, whereas there is no such relationship between CEI increase and yield/rainfall correlations.

To isolate the effect of yield variability on gains of CEI, we compute optimal contracts on all districts and crops, using yields as the weather index: that is, we artificially set the correlation between the index and yields to one. Figure $5 \mathrm{c}$ shows that when the effect of the basis risk is put aside, the gain in CEI depends more clearly on yield variability, although for a given CV large differences between contracts remain. One should note that these gains represent the maximum gains in CEI that could be obtained with a "perfect" weather index on these districts. Even with such an index, the gain in CEI would remain below $2 \%$ for a number of contracts (33 out of 112) for which the yield CV is too low. Finally, the highest values of CEI gains are obtained for districts and crops that exhibit very low-yield values in particular years (Fig. 5d). This results from the utility function used in this study (see section 2b): receiving indemnities in critically low-yield years generates exponentially higher gains in CEI.

Correlations between index and yields, and yield variability, thus seem to be the major determinants of the economic efficiency of the simulated insurance contracts. These two variables, in turn, mainly depend on the cumulative rainfall.

Figure 6 shows that the districts where correlations between rainfall and yield are most satisfactory are generally northern districts. These are districts where total rainfall is low. Because low cumulative rainfall limits crop productivity, yields are, on an interannual time scale, more correlated with rainfall. Conversely, for southern districts where rainfall is more abundant, total rainfall does not strongly limit crop production, thus yield/rainfall correlations tend to be weaker. As a consequence, Fig. 7a shows that the relationship between rainfall and index/ yield correlation is overall negative, albeit with a certain dispersion, even for low cumulative rainfall. Several factors can explain this dispersion. First, cumulative rainfall is not a perfect proxy for yields: for a given rainfall amount, intraseasonal distribution can have significant effects on 

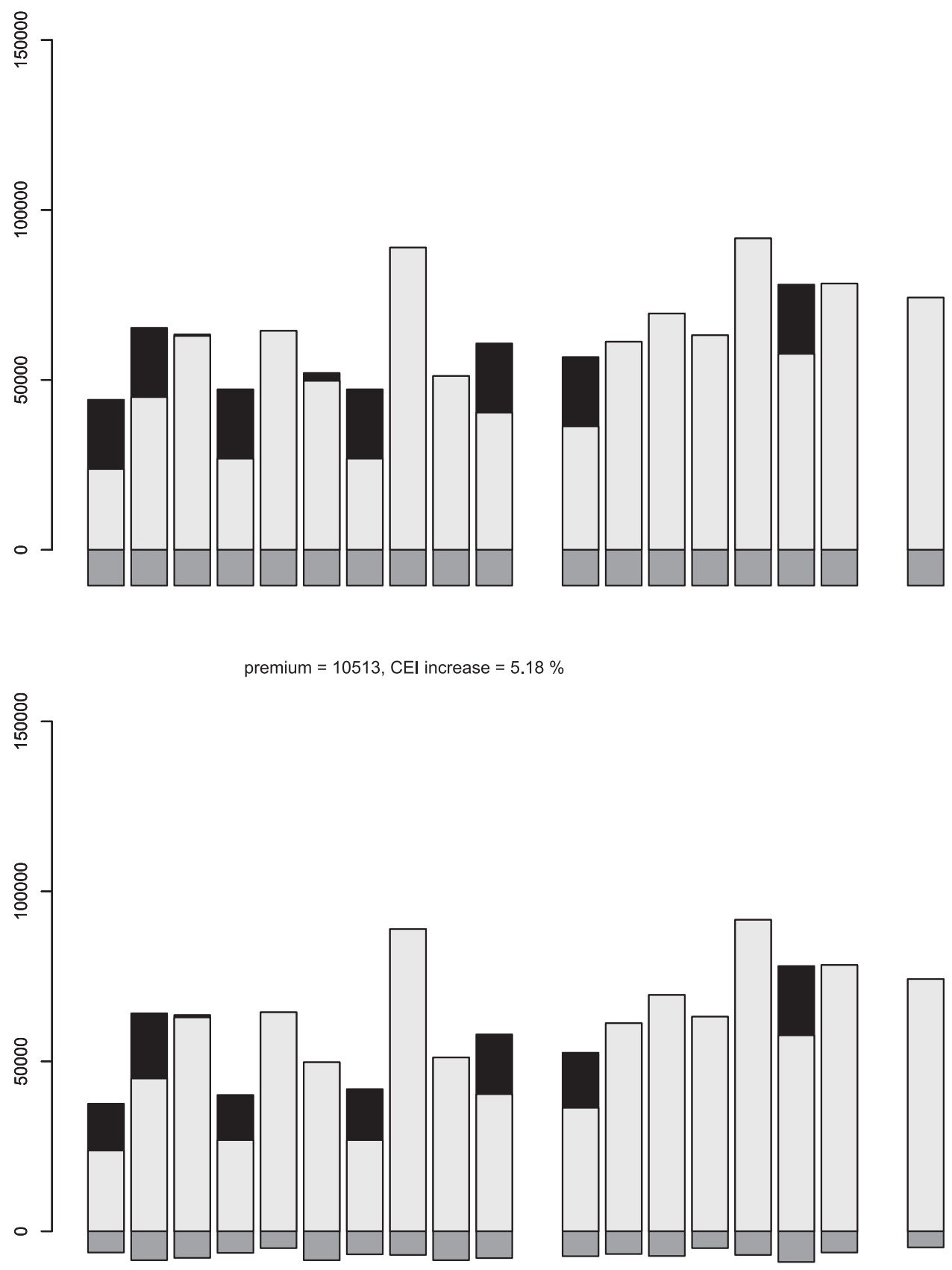

average premium $=6989, \mathrm{CEI}$ increase $=6.72 \%$

FIG. 4. With the same color code as Fig. 3, farmers' income without insurance, indemnities, and annual premium, for a contract for sorghum on the Bam district, (top) optimized over 1984-2004 or (bottom) resulting from a leave-one-out procedure over the same period.

yields (Winkel et al. 1997). Moreover, rainfall is not the only climatic variable impacting yields: radiation and temperature also influence crop productivity. More generally, climate is not the only driver of crop production: nonclimatic factors, for instance the occurrence of pests or farming practices (e.g., sowing date, use of fertilizers) can have significant impacts on yields. In addition, particularly for some vast districts, the locations of the rainfall stations may not correspond to the areas under cultivation, so that the rainfall index does not really 
TABLE 3. For each crop, average gain of CEI (\%) over all districts, when the optimization is performed with different values of risk aversion $R$.

\begin{tabular}{ccccc}
\hline $\begin{array}{c}\text { Coefficient of } \\
\text { risk aversion }\end{array}$ & Millet & Sorghum & Maize & Groundnuts \\
\hline$R=1$ & 0.30 & 0.15 & 2.10 & 1.15 \\
$R=2$ & 2.04 & 1.27 & 11.4 & 6.94 \\
$R=3$ & 6.01 & 3.11 & 30.16 & 23.09 \\
\hline
\end{tabular}

represent the climate experienced by the crops, resulting in weak correlations between rainfall and yields. This is illustrated by the negative correlation between the gain in CEI, for a given crop, and the district area (not shown): contracts over larger districts tend to provide a weaker increase in CEI. Finally, correlations on relatively short time series (21 yr here) are unstable. Each year has an important weight in the correlation coefficient. Hence any 1-yr mismatch between yields and rainfall, for one of the reasons mentioned above, can significantly reduce correlations.

Over the Sudano-Sahelian region, as average total rainfall decreases with latitude, rainfall variability increases (Lebel et al. 2003). Consequently, the stronger correlations between rainfall and yield as rainfall total decreases also tend to result in more variable yields. Figure $7 \mathrm{~b}$ shows that the relation between rainfall and yield variability is also negative. Given the latitudinal gradient in rainfall across the country, this explains why the most efficient contracts tend to be in the northern part of Burkina-Faso (Fig. 2), where yields are more variable and more correlated to rainfall. This also suggests that designing an efficient weather-index insurance system for the southern districts could be difficult, because yields are less variable and less correlated to rainfall.

\section{Discussion and conclusions}

By using a detailed agricultural and climate dataset over Burkina-Faso and very simple assumptions regarding the form of an insurance contract, we investigated the potential feasibility and interest for farmers in a weather-index insurance system in this country. To do so, we explored the results of more than 3000 simulated contracts applied to 30 districts, 21 yr (1984-2004), and five crops (cotton, millet, sorghum, maize, and groundnut). From this large simulation database we found that such an insurance system, even based on a simple weather index like cumulative rainfall during the rainy season, can present a significant economic efficiency: farmers' CEI increases by more than $5 \%$ on average (over all districts and crops), albeit with great variability
TABLE 4. For each crop, average gain of CEI (\%) over all districts, when the optimization is performed with different values of f_max and p_max (f_max $=$ maximum proportion of years with payouts; p_max $=$ maximum ratio of premium to farmer's average income).

\begin{tabular}{ccccc}
\hline \hline $\begin{array}{c}\text { Optimization } \\
\text { constraints }\end{array}$ & Millet & Sorghum & Maize & Groundnuts \\
\hline $\begin{array}{c}\text { f_max }=50 \%, \\
\text { p_max }=20 \%\end{array}$ & 2.04 & 1.27 & 11.4 & 6.94 \\
$\begin{array}{c}\text { f_max }=50 \%, \\
\text { p_max }=10 \%\end{array}$ & 2.04 & 1.03 & 10.36 & 6.89 \\
$\begin{array}{c}\text { f_max }=25 \%, \\
\text { p_max }=20 \%\end{array}$ & 1.95 & 0.88 & 8.2 & 6.33 \\
\hline
\end{tabular}

among contracts from no CEI increase to more than a $100 \%$ increase. The two factors that most influence the viability of such contracts are the correlations between yields and the weather index, and the coefficient of variation of yields. Consequently, we found that the farmers' gain from an insurance contract is higher in the driest part of the country, which is more prone to droughts and exposed to crop failures. In the same way, among the different crops we considered, maize and groundnuts seemed to be the most suitable for implementing an insurance system since their respective yields show a large variance and a generally high correlation with the weather index. We showed that expected utility increase for farmers depends a lot on their assumed risk aversion. Farm-level surveys are thus needed to better assess this aversion and constrain modeling results.

Although our analyses used the same data to optimize contracts and to evaluate payouts and farmer income, a more conservative cross-validated analysis of a subset of the data suggests that overfitting of the optimized contracts did not bias the estimated gain in CEI significantly.

To go further in the assessment of index insurance potential, an essential step would be to use farm-level yield data. Indeed, here we considered contracts on a district level $\left(7000 \mathrm{~km}^{2}\right.$ on average), with a district average yield being representative of a typical individual yield within this district. However, an area-averaged yield is not a perfect surrogate for individual farmers' yields. In particular, spatially averaging yields tends to smooth nonclimatic effects and local heterogeneities, and thus to increase the correlations between yield and rainfall (Sultan et al. 2009). According to the results in section 3, this would lead to our analysis overestimating the gains of CEI for the farmers. On the other hand, yields aggregation also tends to reduce year-to-year variability: this points to an underestimation of CEI gains in our analysis. Investigating the relative importance of these biases would require historical data of individual yields across (at least) one district. Moreover, such data would 

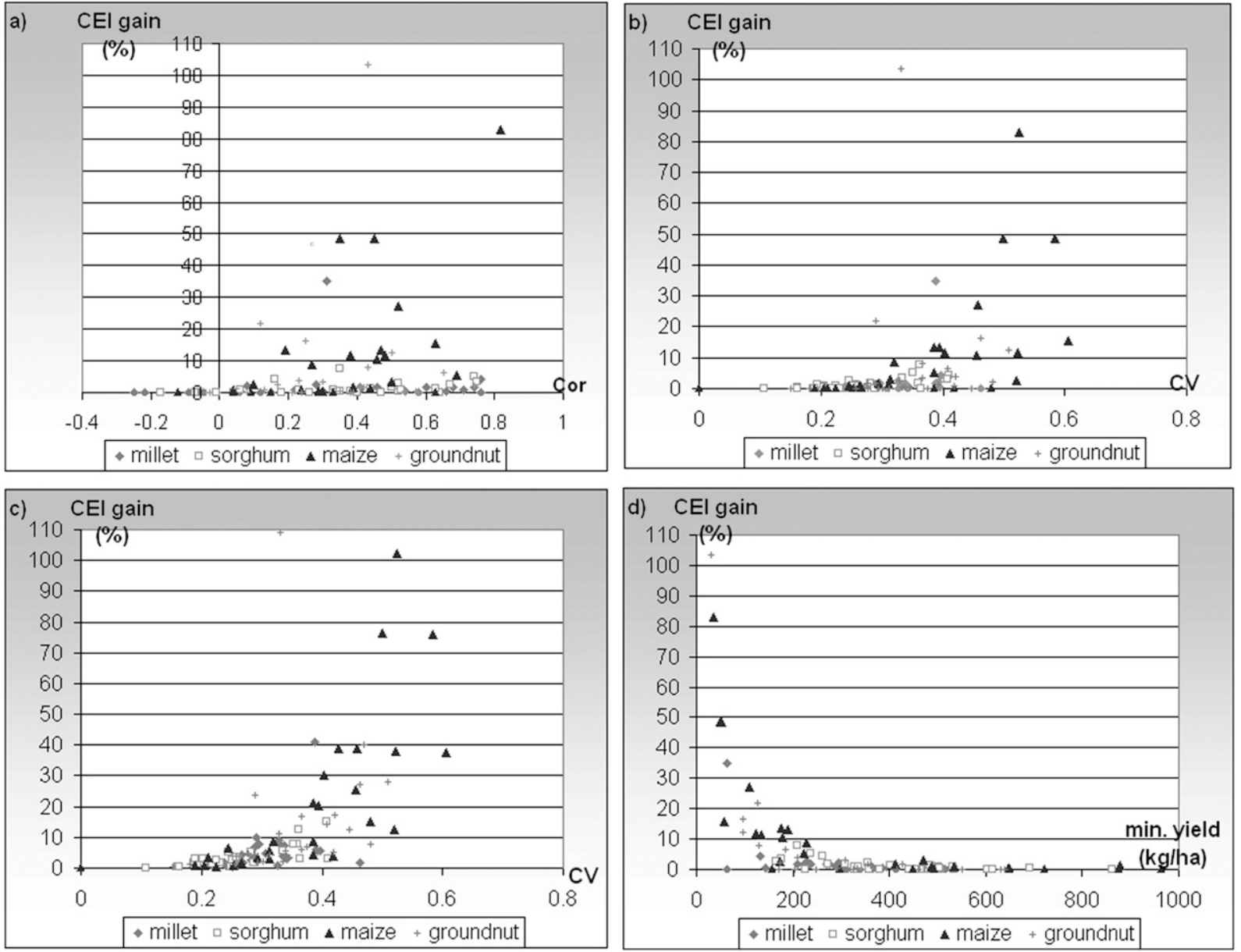

FIG. 5. Gain in CEI for all districts and crops (a) as a function of correlation between index and yield; (b) as a function of the coefficient of variation $[\sigma(X) /$ mean $(X)]$ of yield; (c) as a function of the coefficient of variation of yield, for contracts based on a virtual weather index that perfectly correlates to the yield series; and (d) as a function of the minimum value (in $\mathrm{kg} \mathrm{ha}^{-1}$ ) of the yield time series.

allow the assessment of the spatial basis risk in more detail (i.e., the risk of farmers experiencing different weather from that registered by the index) by analyzing the spatial covariance of yields among farmers. However, we are not aware of such a farm-level yield database currently available in a region like West Africa.

One important simplification in our calculations was to assume linearity between crop yields and farmer's income. Because African rural households already engage in a variety of risk management and coping strategies to reduce income variability (e.g., income diversification, crop diversification, livestock holdings, informal credits), this assumption probably makes our estimate of insurance benefit to farmers optimistic, and should be revisited using farm-level and household data. Historical data on crop prices would also allow us to account for the relationship between prices and yields, which may also smooth farmers' income: generalized crop failure over a given area can be expected to drive crop prices upward. However, this also depends on the balance between the spatial scale of crop market integration and of the area affected by crop failure.

Similarly, our modeling did not assume any change in yield from insurance. However, by covering the risk of climatically induced crop failure, index insurance is often intended as a means to encourage farmers to adopt riskier but more productive farming practices, such as using fertilizers or quality seeds. Thus, a more accurate estimate of insurance benefit to the farmers should account for changes in farming practices and for higher

TABLE 5. Arithmetic mean over all districts of yields, $\mathrm{CV}[\sigma(X) /$ mean $(X)]$, and yield/rainfall correlation for each crop.

\begin{tabular}{lcccc}
\hline & Millet & Sorghum & Maize & Groundnuts \\
\hline Mean yield $\left(\mathrm{kg} \mathrm{ha}^{-1}\right)$ & 645 & 775 & 959 & 726 \\
CV & 0.30 & 0.25 & 0.38 & 0.35 \\
Yield/rainfall correlation & 0.30 & 0.34 & 0.34 & 0.33 \\
\hline
\end{tabular}



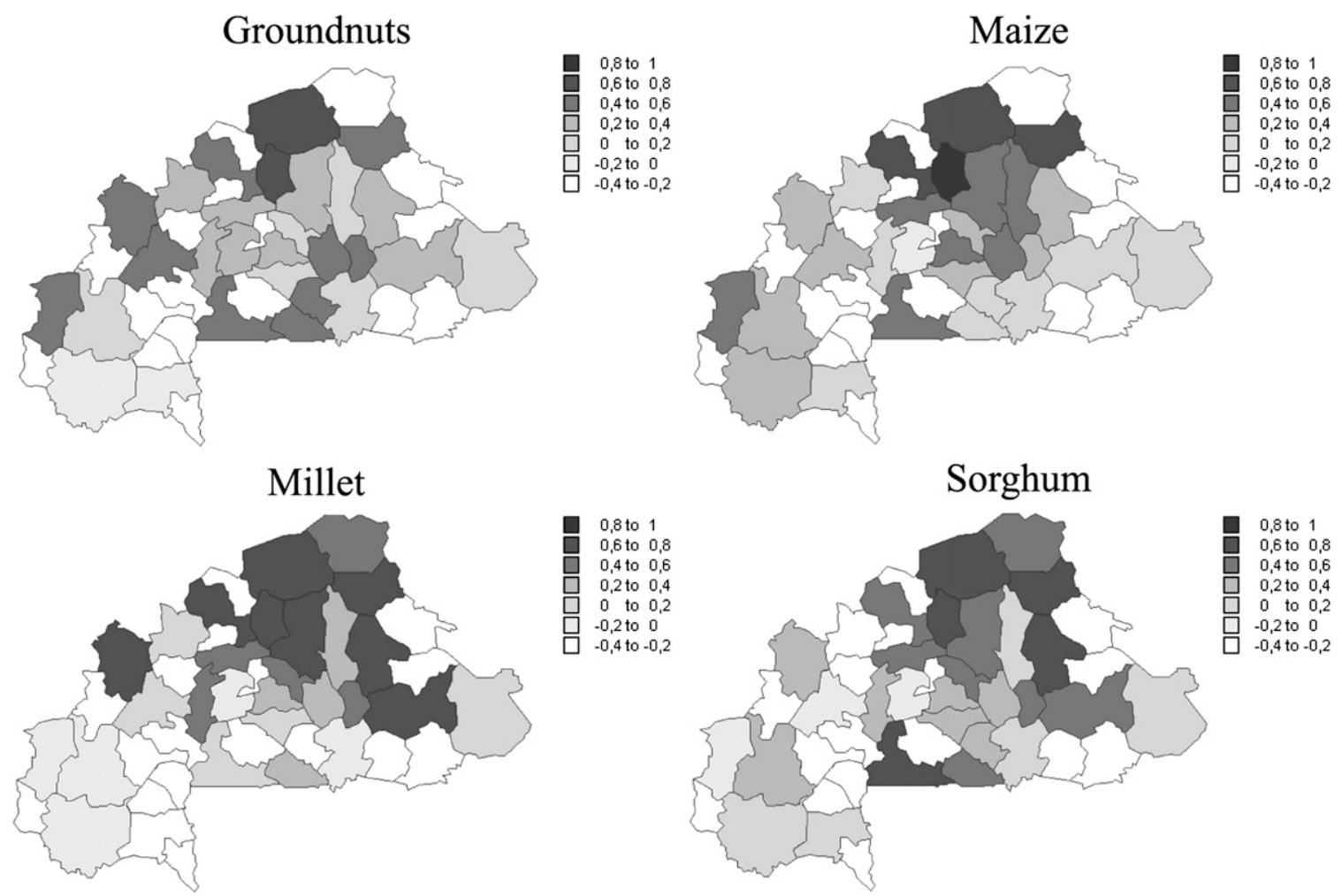

FIG. 6. Correlation between index and yields, over 1984-2004, by districts. Districts in white correspond to missing data (mainly yields), i.e., 15 districts out of 45 .

yields, which in our case suggests that our results may be underestimated.

By design, our modeling approach leaves aside a number of important operational and practical issues. The main one is probably linked to the social acceptability of an agricultural insurance system in rural West Africa. It remains unclear to what extent a formal system of insurance, with official contracts and monetary costs, can be understandable and look attractive and reliable to smallholder farmers in a rural and largely nonliterate environment. This is likely to depend on how the insurance project will be concretely proposed and delivered. One has to define the most efficient interface between the farmers and the insurer (the village, a union of producers, individual farmers, etc.), given, in particular, the inevitable power imbalance between farmers and insurers. The farmers' willingness to pay may also depend on their perception of weather, in particular drought. West African farmers perceive drought as a combination of several parameters: rainy season length, timing and duration of dry spells, rain frequency, etc. (Ingram et al. 2002; Roncoli et al. 2003). If this perception does not coincide with the historical rainfall index used to price the contracts (here, e.g., cumulative rainfall), the farmers may perceive the system as unreliable.
Moreover, the farmers' perception may not be easily compatible with quantitative contract parameters $(S, P)$ expressed in millimeters of rain (Lilleor et al. 2005).

Other practical issues include, for example, the payment of premiums. In theory, the increase in production from insurance is supposed to cover premiums. However, household expenses often quickly consume all cash income in smallholder farming. Premiums may have to be prefinanced through loans and index insurance considered in the frame of a broader agricultural aid system, combined with credit and input supply. For instance, in the pilot project in Malawi, insurance is essentially meant to provide farmers with access to credit and thus to improved inputs (Osgood et al. 2007). The insurance covers the risk faced by lenders that the farmer may not be able to pay back his credit (because of crop failure). In the Sahel, farmers' cash resources are most constrained at the end of the dry season, before the new rainy season: premiums should thus be due earlier in the year. Similarly, if contracts are not priced using seasonal forecast information, insurance transactions should be carried out before forecast are performed, to avoid intertemporal adverse selection (Hess and Syroka 2005). On the other hand, Carriquiry and Osgood (2008) note that if contracts are appropriately designed, there are 

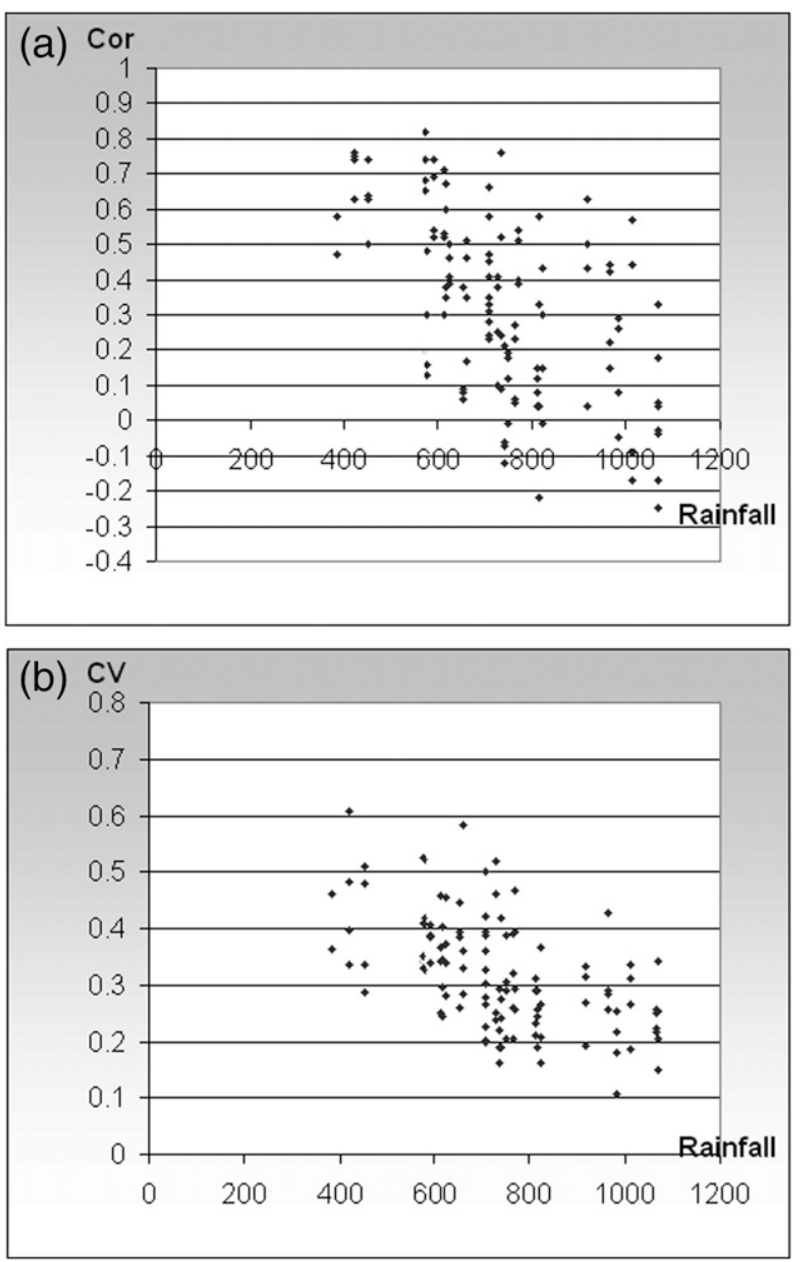

FIG. 7. (a) Correlation (cor) between index and yields and (b) yields coefficients of variation, as a function of cumulative rainfall $(\mathrm{mm})$, all crops and districts.

important synergies between forecasts and insurance and effective input use.

Finally, this study is only based on optimizing the farmer's utility: it does not take into account the particular interests of the insurer, partly because it is not clear what formal rules insurers use to design their contracts. For instance, one should examine the sensitivity of the insurance benefit for the farmers to the insurers' margin. Another important condition for the insurer is to have a portfolio of contracts where risks are uncorrelated or ideally negatively correlated. In the present case, this would depend on the other risks covered by the insurer in other regions, and the possible correlation between the index in Burkina-Faso (rainfall) and these other hazards.

These numerous practical issues naturally warrant further investigation, but it could not be achieved within the modeling framework of this study. Our results thus provide a first-order assessment of the potential of weather-index insurance in Burkina-Faso as a first step for possibly more applied future studies.

Acknowledgments. We would like to gratefully acknowledge the African institutions whose collaboration in the frame of the AMMA project made this study possible: the AGRHYMET Centre in Niamey, which provided us with rainfall data over 1971-2006, and the General Department of Agricultural Forecasts and Statistics of Burkina-Faso, which is in charge of the AGRISTAT agricultural database. We would also like to thank the three anonymous reviewers, whose comments and suggestions significantly contributed to improving this paper.

\section{REFERENCES}

Abdulai, A., and A. CroleRees, 2001: Determinants of income diversification amongst rural households in Southern Mali. Food Policy, 26, 437-452.

Adger, N., and Coauthors, 2007: Summary for policymakers. Climate Change 2007: Impacts, Adaptation and Vulnerability, M. L. Parry et al., Eds., Cambridge University Press, 7-22.

Barnett, B. J., and O. Mahul, 2007: Weather index insurance for agricultural and rural areas in lower-income countries. Amer. J. Agric. Econ., 89, 1241-1247.

_ C. B. Barrett, and J. R. Skees, 2008: Poverty traps and indexbased transfer products. World Dev., 36, 1766-1785.

Barrett, C. B., and Coauthors, 2007: Poverty traps and climate and weather risk: Limitations and opportunities of index-based risk financing. IRI Tech. Rep. 07-03, International Research Institute for Climate and Society, Palisades, NY, $40 \mathrm{pp}$.

Blanc, E., P. Quirion, and E. Strobl, 2008: The climatic determinants of cotton yields: Evidence from a plot in West Africa. Agric. For. Meteor., 148, 1093-1100.

Carriquiry, M., and D. E. Osgood, 2008: Index insurance, probabilistic climate forecasts, and production. Working Paper 08-WP465, Center for Agricultural and Rural Development, $31 \mathrm{pp}$.

Chantarat, S., C. B. Barrett, A. G. Mude, and C. G. Turvey, 2007: Using weather index insurance to improve drought response for famine prevention. Amer. J. Agric. Econ., 89, 1262-1268.

Chavas, J. P., and M. T. Holt, 1996: Economic behaviour under uncertainty: A joint analysis of risk preferences and technology. Rev. Econ. Stat., 78, 329-335.

Cook, K. H., and E. K. Vizy, 2006: Coupled model simulations of the West African monsoon system: 20th and 21st century simulations. J. Climate, 19, 3681-3703.

Dai, A., P. J. Lamb, K. E. Trenberth, M. Hulme, P. D. Jones, and P. Xie, 2004: The recent Sahel drought is real. Int. J. Climatol., 24, 1323-1331.

Deng, X., B. J. Barnett, D. V. Vedenov, and J. W. West, 2007: Using weather-based index insurance to protect against dairy production losses caused by heat stress. Agric. Econ., 36, 271-280.

De Rouw, A., 2004: Improving yields and reducing risks in pearl millet farming in the African Sahel. Agric. Syst., 81, 73-93.

Giné, X., R. Townsend, and J. Vickery, 2007: Statistical analysis of rainfall insurance payouts in Southern India. Amer. J. Agric. Econ., 89, 1248-1254. 
Gollier, C., 2003: To insure or not to insure?: An insurance puzzle. Geneva Pap. Risk Insur. Theory, 28 (1), 5-24.

Hartell, J., H. Ibarra, J. Skees, and J. Syroka, 2006: Risk management in agriculture for natural hazard. ISMEA, $201 \mathrm{pp}$.

Hess, U., and J. Syroka, 2005: Weather-based insurance in Southern Africa: The case of Malawi. Agricultural and Rural Development Discussion Paper 13, The World Bank, 67 pp.

_ J. R. Skees, A. Stoppa, B. J. Barnett, and J. Nash, 2005: Managing agricultural production risk: Innovations in developing countries. Agriculture and Rural Development Department Rep. 32727-GLB, World Bank, 86 pp.

Ingram, K. T., M. C. Roncoli, and P. H. Kirshen, 2002: Opportunities and constraints for farmers of West Africa to use seasonal precipitation forecasts with Burkina Faso as a case study. Agric. Syst., 74, 331-349.

Lebel, T., A. Diedhiou, and H. Laurent, 2003: Seasonal cycle and interannual variability of the Sahelian rainfall at hydrological scales. J. Geophys. Res., 108, 8389, doi:10.1029/2001JD001580.

Lilleor, H. B., X. Giné, R. Townsend, and J. Vickery, 2005: Weather insurance in semi-arid India. World Bank Working Paper, 24 pp.

Mahul, O., 2001: Optimal insurance against climatic experience. Amer. J. Agric. Econ., 83, 593-604.

McLeman, R., and B. Smit, 2006: Vulnerability to climate change hazards and risks: Crop and flood insurance. Can. Geogr., 50 (2), 217-226.

Osgood, D. E., M. McLaurin, M. Carriquiry, A. Mishra, F. Fiondella, J. Hansen, N. Peterson, and N. Ward, 2007: Designing weather insurance contracts for farmers in Malawi, Tanzania, and Kenya. Final Rep. to the Commodity Risk Management Group, ARD, World Bank, IRI, Columbia University, 100 pp.

Pope, R. D., and R. E. Just, 1991: On testing the structure of risk preferences in agricultural supply system. Amer. J. Agric. Econ., 73, 743-748.

Roncoli, C., K. Ingram, P. Kirshen, and C. Jost, 2003: Meteorological meanings: Understandings of seasonal rainfall forecasts by farmers of Burkina Faso. Weather, Climate, Culture, S. Strauss and B. Orlove, Eds., Berg, 181-202.
Sakurai, T., and T. Reardon, 1997: Potential demand for drought insurance in Burkina Faso and its determinants. Amer. J. Agric. Econ., 79, 1196-1207.

Skees, J. R., P. Hazell, and M. Miranda, 1999: New approaches to crop insurance in developing countries. EPTD Discussion Paper 55, International Food Policy Research Institute, Washington, DC, $40 \mathrm{pp}$.

, P. Varangis, R. Lester, S. Gober, and V. Kalavakonda, 2001: Developing rainfall-based index insurance in Morocco. World Bank Policy Research Working Paper 2577, 39 pp.

_ - J. Hartell, and A. G. Murphy, 2007: Using index-based risk transfer products to facilitate micro lending in Peru and Vietnam. Amer. J. Agric. Econ., 89, 1255-1261.

Sultan, B., M. Bella-Medjo, A. Berg, P. Quirion, and S. Janicot, 2009: Multi-scales and multi-sites analyses of the role of rainfall in cotton yields in West Africa. Int. J. Climatol., in press, doi:10.1002/joc. 1872 .

Trenberth, K. E., and Coauthors, 2007: Observations: Surface and atmospheric climate change. Climate Change 2007: The Physical Science Basis, S. Solomon et al., Eds., Cambridge University Press, 237-336.

Turvey, C. G., 2001: Weather derivatives for specific event risks in agriculture. Rev. Agric. Econ., 23 (2), 333-351.

Vedenov, D. V., and B. J. Barnett, 2004: Efficiency of weather derivates as primary crop insurance instruments. J. Agric. Resour. Econ., 29 (3), 387-403.

Ward, M. N., E. M. Holthaus, and A. Siebert, 2008: Index insurance for drought in the Millennium Villages Project. Preprints, 20th Conf. on Climate Variability and Change, New Orleans, LA, Amer. Meteor. Soc., P1.9.

Winkel, T., J.-F. Renno, and W. A. Payne, 1997: Effect of the timing of water deficit on growth, phenology and yield of pearl millet (Pennisetum glaucum (L.) R. Br.) grown in Sahelian conditions. J. Exp. Bot., 48, 1001-1009.

World Bank, 2007: Africa development indicators 2007. World Bank, Washington, DC, 166 pp.

Wouterse, F., and J. E. Taylor, 2007: Migration and income diversification: Evidence from Burkina-Faso. World Dev., 36, 625-640. 